Gut, 1978, 19, 1022-1026

\title{
Hepatocellular carcinoma in Great Britain: influence of age, sex, HBsAg status, and aetiology of underlying cirrhosis
}

\author{
P. J. JOHNSON, N. KRASNER, B. PORTMANN, A. L. W. F. EDDLESTON, AND \\ ROGER WILLIAMS
}

From the Liver Unit, King's College Hospital and Medical School, London

SUMMARY An analysis of 294 patients who died with cirrhosis showed that $24 \%$ had developed hepatocellular carcinoma. Haemochromatosis and HBsAg positive chronic active hepatitis were high risk groups (36\% and $42 \%$ respectively) and the frequency was lowest in primary biliary cirrhosis and HBsAg negative chronic active hepatitis (3\% and $11 \%$ respectively). Those with hepatocellular carcinoma showed a striking male preponderance $(11: 1)$ and further analysis has shown that the proportion developing this tumour in each group was closely related to the proportion of males in that group $(r=0.97)$. Age was the only other significant factor, malignant change occurring more commonly in those over the age of 50 years than those below $(30 \%$ and $7 \%$ respectively, $\mathrm{P}<0.005)$. The influence of HBsAg was largely accounted for by the known predisposition of males to carry HBsAg. The group of patients who had developed this tumour without cirrhosis were younger (mean age 39 years) and had a lower male to female ratio of $1 \cdot 1: 1$ and the place of contraceptive-related tumour within this group is discussed.

It is well recognised that hepatocellular carcinoma may develop in longstanding cirrhosis (Stewart, 1931; Berman, 1951; Gall, 1960), though the reported frequency varies both from country to country (Doll et al., 1966) and with the underlying aetiology (Powell et al., 1971). In parts of Africa and the Far East where the incidence is high, environmental factors, such as aflatoxin and the hepatitis B virus, may be important (Vogel et al., 1970; Alpert et al., 1971). Indeed, in these populations up to $80 \%$ of patients have HBsAg present in their serum and the most widely held view is that the tumour has developed from a cirrhosis related to the hepatitis B infection (Tong et al., 1971). In low incidence areas such as Europe and the USA, the frequency of $\mathrm{HBsAg}$ carriage is much lower, though progression of HBsAg positive chronic active hepatitis to hepatocellular carcinoma is well recognised. In the latter areas less than $30 \%$ of cases arise in an otherwise normal liver. Within that group are the recently reported instances of this tumour arising in young women taking the contraceptive pill (Christopherson et al., 1975; Davis et al., 1975; Christopherson and Mays, 1976), and males ingesting androgenic ster-

Received for publication 8 June 1978 oids (Johnson et al., 1972; Farrell et al., 1975), both of which suggest the additional influence of hormonal factors.

In this paper we analyse the influence of age, sex, HBsAg status, and aetiology of underlying cirrhosis on the frequency of hepatocellular carcinoma development in 294 British patients dying of cirrhosis and the relative importance of these factors in 25 other patients in whom no evidence of an underlying cirrhosis was found.

\section{Methods}

The case notes of all British patients seen at King's College Hospital who were recorded as dying with hepatocellular carcinoma, or as a result of cirrhosis, between 1967 and 1975 were analysed. These comprised 294 patients with cirrhosis, in $71(24 \%)$ of whom hepatocellular carcinoma had been detected either during life or at necropsy, and 25 who had developed carcinoma in an otherwise normal liver. In all cases the diagnosis of cirrhosis and the presence of hepatocellular carcinoma were confirmed by histological examination of liver biopsy tissue. Other types of primary liver tumour, such as cholangiocarcinoma and heamangiosarcoma, were ex- 
cluded from the final series. Hepatitis B surface antigen (HBsAg) was tested for either by radioimmunoassay or passive haemagglutination in 178 $(60.5 \%)$ cases, 116 cases presenting before HBsAg testing became routinely available. Over the past three years we have examined all sera for HBsAg by both methods and have found that radioimmunoassay leads to an increase of less than $5 \%$ in the frequency of detection as compared with the haemagglutination method.

\section{Results}

Of the 294 patients with cirrhosis, there were marked differences in aetiology among the 71 with hepatocellular carcinoma (Table 1). Thus patients with haemochromatosis and $\mathrm{HBsAg}$ positive chronic hepatitis had a high incidence of tumour development ( $36 \%$ and $42 \%$ respectively), whereas those with antigen negative chronic hepatitis and primary biliary cirrhosis had low figures $(11 \%$ and $3 \%$ respectively). Alcoholic and cryptogenic cirrhosis formed an intermediate group, though the risk of malignant change was still high $(25 \%$ and $27 \%$ respectively).

Table 1 Incidence of hepatocellular carcinoma in different types of cirrhosis

\begin{tabular}{|c|c|c|c|c|c|}
\hline \multirow[t]{2}{*}{ Type of cirrhosis } & \multirow{2}{*}{$\begin{array}{l}\text { Patients } \\
\text { (no.) }\end{array}$} & \multirow{2}{*}{$\begin{array}{l}\text { Males } \\
(\%)\end{array}$} & \multirow{2}{*}{$\begin{array}{l}\text { With HCC } \\
(\%)\end{array}$} & \multicolumn{2}{|c|}{ Mean age at death $(y r)$} \\
\hline & & & & Cirrhosis & HCC \\
\hline Alcoholic & 85 & 65 & 25 & 52 & 63 \\
\hline Cryptogenic & 71 & 65 & 27 & 54 & 58 \\
\hline \multicolumn{5}{|l|}{ Haemochroma- } & 63 \\
\hline $\begin{array}{l}\text { Primary biliary } \\
\text { Chronic active } \\
\text { hepatitis }\end{array}$ & 31 & 6 & 3 & 55 & 70 \\
\hline HBsAg positive & 12 & 92 & 42 & 41 & 54 \\
\hline HBsAg negative & 36 & 42 & 11 & 40 & 54 \\
\hline
\end{tabular}

To determine the relative importance of $\mathrm{HBsAg}$ in the development of hepatocellular carcinoma, each aetiological group was subdivided into those patients developing hepatocellular carcinoma and those with cirrhosis alone and the frequency of HBsAg was compared in the two subgroups (Table 2). Only in patients with CAH was there a significantly increased association between $\mathrm{HBsAg}$ and hepatoma $(P<0.01)$ development, although in the patients with alcoholic and cryptogenic cirrhosis the numbers are too small for accurate statistical analysis. However, when only males with $\mathrm{CAH}$ were considered no association is found between $\mathrm{HBsAg}$ and hepatoma development $(P>0 \cdot 1)$ showing that the apparent association between these two factors is entirely due to the association of both these factors with the male sex. Indeed, while the male:female ratio for the whole cirrhotic group was less than 2:1, the corresponding figure for those developing tumour was $11: 1(\mathrm{P}<0.0005)$. The association between male sex and hepatocellular carcinoma is reflected in each aetiological group, and the groups with the greatest percentage of males (haemochromatosis and antigen positive chronic active hepatitis) have the highest frequency of tumour development. Conversely, in the antigen negative chronic active hepatitis and primary biliary cirrhosis groups, where females predominate, the frequency is much lower. The relationship between frequency of tumour development of a particular aetiology and the percentage of males was linear and statistically highly significant (Fig. 1).

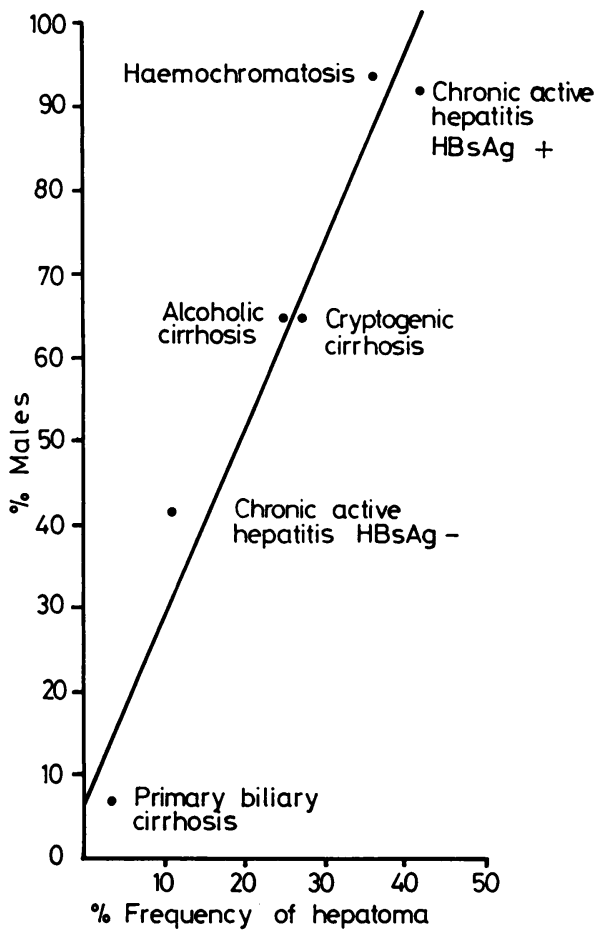

Fig. 1 Relationship between percentage of males and frequency of tumour development in different aetiological groups $(\mathrm{r}=0.93)$.

Another factor of relevance to tumour frequency appears to be age. The mean age of those with tumour was 61 years compared with 53 years for those dying of cirrhosis without evidence of tumour, and this difference occurred in each aetiological group. When the frequency of death below the age of 50 years in cirrhotic patients with and without tumour development is considered, there were only five patients under the age of 50 years with tumour 
Table 2 HBsAg status of cirrhotic patients with and without hepatocellular carcinoma

\begin{tabular}{|c|c|c|c|}
\hline \multirow{2}{*}{$\frac{\text { Type of cirrhosis }}{\text { Chronic active hepatit }}$} & \multirow[t]{2}{*}{ Cirrhosis } & \multicolumn{2}{|c|}{ Cirrhosis + HCC } \\
\hline & & & \\
\hline HBsAg + & 7 & 5 & $P<0.01$ \\
\hline HBsAg - & 32 & 4 & \\
\hline Alcoholic & & & NS \\
\hline HBsAg + & 1 & 4 & \\
\hline HBsAg - & 24 & 13 & \\
\hline Cryptogenic & & & NS \\
\hline HBsÄg + & 3 & 3 & \\
\hline HBsAg - & 17 & 9 & \\
\hline Haemochromatosis & & & NS \\
\hline HBsAg + & 0 & $\mathbf{0}$ & \\
\hline HBsAg - & 20 & 4 & \\
\hline Primary biliary & & & NS \\
\hline HBsAg + & $\mathbf{0}$ & 0 & \\
\hline HBsAg - & 31 & 1 & \\
\hline
\end{tabular}

HCC: hepatocellular carcinoma; NS: not statistically significant.

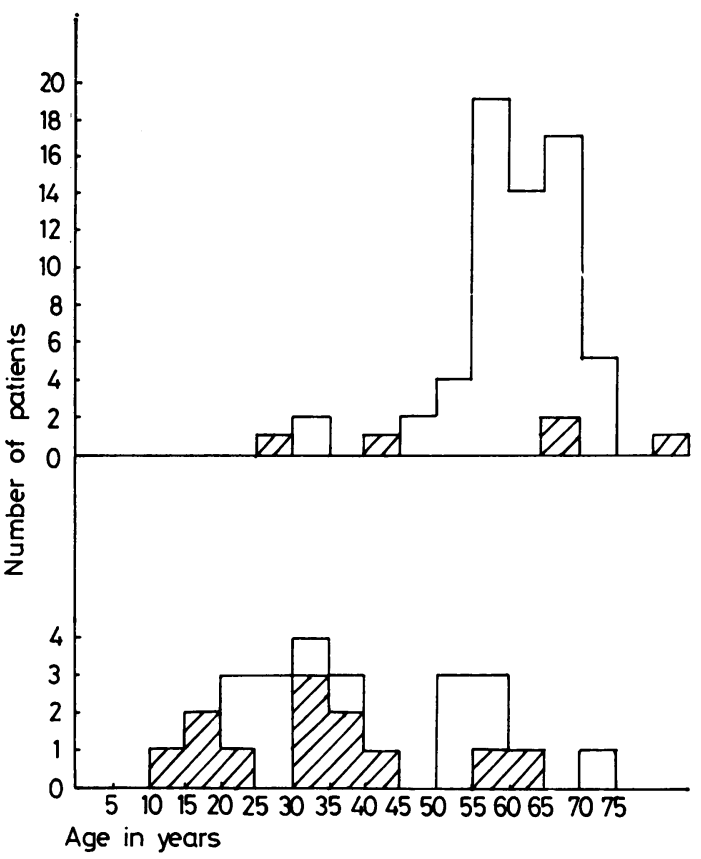

Fig. 2 Age and sex distribution of patients with hepatocellular carcinoma, with and without underlying cirrhosis. (Shaded areas represent females, unshaded areas males.)

compared with 66 patients without (Fig. 2). The distribution of males and females above and below the age of 50 years was not statistically significant $(P>0 \cdot 1)$. Further statistical analysis (Table 3$)$ on the influence of age and sex together confirmed that both factors affected the incidence of hepatoma in cirrhosis.
Table $34 \times 2 \chi^{2}$ table of factors, age and sex on development of hepatoma in cirrhosis

\begin{tabular}{cllc}
\hline & \multicolumn{2}{l}{ Number of cases } & Total \\
\cline { 2 - 3 } & With hepatoma & Without hepatoma & \\
\hline Females & & 37 & \\
$<50$ yr & 2 & 78 & 39 \\
$>50 \mathrm{yr}$ & 4 & 39 & 82 \\
Males & 4 & 69 & 43 \\
$<50 \mathrm{yr}$ & 4 & 223 & 130 \\
$>50 \mathrm{yr}$ & 61 & 294 \\
\hline Total & 71 & \\
\hline
\end{tabular}

$x^{2}>50, P<0.001$ (degrees of freedom 3 ). This indicates that both age and sex influence the development of hepatoma in cirrhosis.

There were striking differences between patients with hepatocellular carcinoma without cirrhosis and those with underlying cirrhosis, in respect of both age and sex. Thus, the male:female ratio of $1.1: 1$ is very different from the 11:1 of the cirrhotic group. The mean age of 39 years was not only lower but the distribution was broader and showed a tendency to be bimodal with peaks at 25-35 years and 55-60 (Fig. 2 ), whereas those with cirrhosis had a single peak at 60-65 years (mean 61.5 years). Of 12 women patients in this group, four had taken the oral contraceptive pill for variable periods of time (three of these were still taking it at the time of diagnosis of the tumour), four had never used this method of contraception and in four the information was not available. In one of the cases associated with the contraceptive pill, the histological abnormalities were of particular interest, since the resected tumour showed areas of peliosis hepatis, benign adenoma, and other areas with definite hepatocellular carcinoma (Davis et al., 1975).

There may also have been familial influences, as $\mathbf{1 0}$ of 16 patients in whom detailed family history was available had first-degree relatives with various forms of cancer, particularly the rarer types such as leukaemia (two), Hodgkin's disease (one), and adrenal carcinoma (one). In another family the father had also died of primary liver carcinoma. One patient, who had been successfully treated by a liver transplantation, had a younger brother who had died of hepatocellular carcinoma. Both of these, as well as a third brother, were HBsAg positive, though liver biopsy in the latter showed no evidence of tumour development (Johnson et al., 1977). Only one other patient in this group was $\mathrm{HBsAg}$ positive giving an overall incidence in the 21 patients tested of $9 \%$.

\section{Discussion}

The $24 \%$ overall frequency of hepatocellular carcinoma in the present series is rather higher than that reported for other series of cirrhotic patients in Britain. MacSween (1974), working in a general 
hospital in Scotland, found an incidence of $18 \%$ for the years 1960-69, which is identical to that reported by Stone et al. (1968) between 1959 and 1965 from Birmingham. However, as the present series comes from a referral centre, it is not strictly comparable, and analysis of the frequency of tumour development in different types of cirrhosis gives more meaningful statistics. Thus, the figure of $25 \%$ in the alcoholic group is similar to those of $33 \%$ found by Stone et al. (1968) and $30 \%$ found by Lee (1966), though this is much higher than reported in the USA. In those with cryptogenic cirrhosis, however, the frequency is much higher than that found by Stone et al. $(29 \%$ compared to $11 \%$ ).

Most authors have considered that the cirrhosis of haemochromatosis is the type most likely to undergo malignant transformation (Walker and Williams, 1974). As discussed in detail elsewhere (Bomford and Williams, 1976), hepatocellular carcinoma developed only in those patients with haemochromatosis who had developed definite cirrhosis at the time of diagnosis. Furthermore, several patients developed tumour despite complete removal of excess iron by venesection therapy and sometimes many years later, suggesting that malignant change may be related to cirrhosis rather than iron overload per se.

The single patient developing hepatocellular carcinoma with primary biliary cirrhosis (Davidson $e t$ al., 1974) had had cirrhosis, diagnosed at laparotomy, for at least 10 years. This is unusual, since the mean survival from the time of diagnosis for patients with primary biliary cirrhosis is only five years (Sherlock, 1959). This, together with the finding that patients with hepatocellular carcinoma were significantly older than those dying of other complications, further supports the contention that duration of cirrhosis is an important factor in tumour development. However, cirrhosis may not produce symptoms for several years and this makes direct estimation of duration difficult. Indeed, in the present series $28 \%$ of the patients were not seen until manifestation of the tumour had become evident.

The preponderance of males among the patients developing hepatocellular carcinoma is also apparent in most other series. For example, Stone et al. (1968) found $86 \%$, Parker (1957) $88 \%$, and MacSween (1974) $92 \%$ males, and our figure agrees with these. The reasons for this must remain speculative but there is considerable evidence that in animals testosterone increases the evidence of, and castration affords protection against, spontaneous and chemically-induced hepatic tumour (Agnew and Gardner, 1952; Reuber, 1969). There are also the recent reports of hepatocellular carcinoma occurring in males taking oral testosterone (Johnson et al., 1972; Farrell et al., 1975).
If the hepatitis B virus were an important factor in the progression of cirrhosis to hepatocellular carcinoma it would be expected that $\mathrm{HBsAg}$ would be found significantly more frequently in those with cirrhosis and tumour than in those with cirrhosis alone. Our results do not support this and rather are consistent with the idea that the hepatitis $B$ virus is one of many factors associated with the development of cirrhosis and that progression to malignant change depends on the sex and age of the patient. When assessing the importance of $\mathrm{HBsAg}$ in this context it is important to have a control group of cirrhotic patients (rather than normal subjects) who are matched for sex and aetiology. However, in patients who develop tumours without cirrhosis the frequency of $\mathrm{HBsAg}$ may be compared directly with the normal population. Although a figure of $9.5 \%$ is greater than would be expected by chance in a normal British population (less than $0 \cdot 1 \%$ ) the number of patients is too small for valid statistical analysis. This does suggest, however, that carriers of HBsAg may be at an increased, though very small, risk of developing hepatocellular carcinoma.

The bimodal age distribution of the patients without cirrhosis has been noted in a smaller series by Shikata in Japan (1976). The slight male predominance in this group is also in agreement with others, MacSween (1974) finding a male:female ratio of 2:1 and Peters 1·1:1 (1976). The finding that these patients appear to have a high incidence of cancer in their families may suggest an underlying genetic factor. Our family-in which two young brothers, apparently healthy carriers of $\mathrm{HBs} A g$, both developed hepatocellular carcinoma-illustrates the complex genetic/environmental inter-relationships which may be at play. This also applies to the apparent association with the contraceptive pill. Both benign and malignant liver tumours have been associated with its use (Baum et al., 1973; Christopherson et al., 1975; Christopherson and Mays, 1976; Shikata, 1976). Our patient, in whom both types of histology were found within the one tumour mass, is of particular interest (Davis et al., 1975). Although the relationship must be extremely rare, if it is dependent on the duration of contraceptive pill usage an increasing number of cases are to be expected. There is no doubt, however, that the tumour can develop in women who have never taken this pill and, with increasingly frequent use of the contraceptive pill, one would find an apparent increase in the total number of women developing hepatocellular carcinoma while on the pill, even if there were no casual relationship. A more accurate statistical analysis of the situation would be possible if all cases of hepatocellular carcinoma without cirrhosis were reported. If the male:female ratio 
altered from the present figure of about 1.5:1 to become more common in females this would be strong evidence for a casual relationship.

Since the completion of this analysis we have seen a further 50 cases of hepatocellular carcinoma in British patients. All 30 of those in whom there was underlying cirrhosis were male and over the age of 50 years.

We are grateful to $\mathrm{Mr} \mathbf{H}$. Y. Ton for statistical advice and to Linda Rimmer for editorial assistance. The Cancer Research Campaign provided financial assistance and P. J. Johnson was supported by a Saltwell Research Fellowship from the Royal College of Physicians.

\section{References}

Agnew, L. R. C., and Gardner, W. U. (1952). The incidence of spontaneous hepatomas in $\mathrm{C}_{3} \mathrm{H}, \mathrm{C}_{3} \mathrm{H}$ (low milk factor), and CBA mice and the effect of estrogen and androgen on the occurrence of these tumors in $\mathrm{C}_{3} \mathrm{H}$ mice. Cancer Research, 12, 757-761.

Alpert, M. E., Hutt, M. S. R., Wogan, G. N., and Davidson, C. S. (1971). Association between aflatoxin content of food and hepatoma frequency in Uganda. Cancer, 28, 253-260.

Baum, J. K., Holtz, F., Bookstein, J. J., and Klein, E. W. (1973). Possible association between benign hepatomas and oral contraceptives. Lancet, 2, 926-929.

Berman, C. (1951). Primary Carcinoma of the Liver: a Study in Incidence, Clinical Manifestations, Pathology, and Aetiology. Lewis: London.

Bomford, A., and Williams, R. (1976). Long term results of venesection therapy in idiopathic haemochromatosis. Quarterly Journal of Medicine, 45, 611-623.

Christopherson, W. M., and Mays, E. T. (1976). Liver tumours and oral contraceptives (Letter). Lancet, 1, 1076.

Christopherson, W. M., Mays, E. T., and Barrows, G. H. (1975). Liver tumors in women on contraceptive steroids. Obstetrics and Gynecology, 46, 221-223.

Davidson, A. R., Tomlinson, S., Calne, R. Y., and Williams, R. (1974). The variable course of primary hepatocellular carcinoma. British Journal of Surgery, 61, 349-352.

Davis, M., Portmann, B., Searle, M., Wright, R., and Williams, R. (1975). Histological evidence of carcinoma in a hepatic tumour associated with oral contraceptives. British Medical Journal, 4, 496-498.

Doll, R., Payne, P., and Waterhouse, J. eds. (1966). Cancer Incidence in Five Continents. Springer: for International Union against Cancer. Berlin.

Farrell, G. C., Uren, R. F., Perkins, K. W., Joshua, D. E.,
Baird, P. J., and Kronenberg, H. (1975). Androgen-induced hepatoma. Lancet, 1, 430-432.

Gall, E. A. (1960). Primary and metastatic carcinoma of the liver. Archives of Pathology, 70, 226-232.

Johnson, F. L., Feagler, J. R., Lerner, K. G., Majerus, P. W., Siegel, M., Hartmann, J. R., and Thomas, E. D. (1972). Association of androgenic-anabolic steroid therapy with development of hepatocellular carcinoma. Lancet, 2, 12731276.

Johnson, P. J., Wansbrough-Jones, M. H., Portmann, B., Eddleston, A. L. W. F., Williams, R., Maycock, W. d'A., and Calne, R. Y. (1977). Familial occurrence of HBsAg positive hepatoma: treatment by orthotopic liver transplantation and specific immunoglobulin. British Medical Journal. (In press.)

Lee, F. I. (1966). Cirrhosis and hepatoma in alcoholics. Gut, 7, 77-85.

MacSween, R. N. M. (1974). A clinicopathological review of 100 cases of primary malignant tumours of the liver. Journal of Clinical Pathology, 27, 669-682.

Parker, R. G. F. (1957). The incidence of primary hepatic carcinoma in cirrhosis. Proceedings of the Royal Society of Medicine, 50, 145-147.

Peters, R. L. (1976). Pathology of hepatocellular carcinoma. In Hepatocellular Carcinoma. pp. 107-168. Edited by K. Okuda and R. L. Peters. Wiley: New York.

Powell, L. W., Mortimer, R., and Harris, O. D. (1971). Cirrhosis of the liver-a comparative study of the four major aetiological groups. Medical Journal of Australia, 71, 941-950.

Reuber, M. D. (1969). Influence of hormones on $\mathrm{N}-2$ fluorenyldiacetamide-induced hyperplastic hepatic nodules in rats. Journal of the National Cancer Institute, 43, 445-451.

Sherlock, S. (1959). Primary biliary cirrhosis (chronic intrahepatic obstructive jaundice). Gastroenterology, 37, 574-586.

Shikata, T. (1976). Primary liver carcinoma and liver cirrhosis. In Hepatocellular Carcinoma, pp. 53-71. Edited by $\mathrm{K}$. Okuda and R. L. Peters. Wiley: New York.

Stewart, M. J. (1931). Precancerous lesions of the alimentary tract. Lancet, 2, 565-572.

Stone, W. D., Islam, N. R. K., and Paton, A. (1968). The natural history of cirrhosis. Quarterly Journal of Medicine, 37, 119-132.

Tong, M. J., Sun, S., Schaeffer, B. T., Chang, N., Lo, K., and Peters, R. L. (1971). Hepatitis-associated antigen and hepatocellular carcinoma in Taiwan. Annals of Internal Medicine, 75, 687-691.

Vogel, C. L., Anthony, P. P., Mody, N., and Barker, L. F. (1970). Hepatitis-associated antigen in Ugandan patients with hepatocellular carcinoma. Lancet, 2, 621-624.

Walker, R. J., and Williams, R. (1974). Haemochromatosis and iron overload. In Iron in Biochemistry and Medicine, Edited by A. Jacobs and M. Worwood. Academic Press: London. 